\title{
Clicker Sets as Learning Objects
}

\section{Gerald Bergtrom \\ Biological Sciences Department and Learning Technology Center, University of Wisconsin-Milwaukee, Milwaukee, WI, USA}

\author{
bergtrom@uwm.edu
}

\begin{abstract}
Science courses were among the earliest adopters of student response systems, more commonly called clickers, because they engage students in collaborative activities on a scale not heretofore possible in large lecture halls. Standard explanatory slides are interspersed with interactive questions to which students enter responses by pressing a key on a response device (the clicker). By criteria found to be acceptable in several studies, a series of these standard and interactive slides that encourage critical thinking about important concepts or experiments constitutes a limited content learning object. Examples of paired, matched-content sets of non-interactive and clicker (i.e., interactive) slides for use by students at home and by the instructor in class are presented to illustrate uniquely powerful, mutually reinforcing learning objects.
\end{abstract}

Keywords: student response systems, student response systems, clickers, PowerPoint ${ }^{\mathrm{tm}}$

\section{Introduction}

To understand what a learning object is, consider the operative word object in the phrase. An object is a proscribed (limited) packet of information about topic or concept that is embedded in a larger body of related information. Inherent in the term learning object is the idea that a large body of information about a subject is more easily learned in smaller conceptual packets that can be viewed as part of, or later assembled into a coherent whole. This malleability of learning objects explains why they play an important role in the "flexible teaching and learning and... delivery" of online courses (de Salas \& Ellis, 2006). By their very nature, effective online courses use flexible teaching strategies to give students "control over when, what, where, how and at what pace they learn" (Johnston, 2001). On the other hand, the learning objects to be described here combine elements of digitally enhanced self-directed learning with student engagement in an otherwise traditional classroom. Because of their divergent forms and uses, it has proven hard to arrive at a universally acceptable definition of a learning object.

In examining descriptions of learning objects Wiley (2000) noted that overly inclusive definitions are not useful and recognized the need to "narrow the scope" of the definition. Wiley settles on

Material published as part of this journal, either on-line or in print, is copyrighted by the publisher of the Interdisciplinary Journal of Knowledge and Learning Objects. Permission to make digital or paper copy of part or all of these works for personal or classroom use is granted without fee provided that the copies are not made or distributed for profit or commercial advantage AND that copies 1) bear this notice in full and 2) give the full citation on the first page. It is permissible to abstract these works so long as credit is given. To copy in all other cases or to republish or to post on a server or to redistribute to lists requires specific permission and payment of a fee. Contact Publisher@ijklo.org to request redistribution permission. the definition of a learning object as any digital resource that can be reused to support learning. But even 5 years later, multiple definitions persist. Harman and Koohang (2005) reviewed different definitions of learning objects in terms of object structure and content. From the various definitions, these authors suggest that a learning object is either digital or not, often tagged with metadata, 
typically contextual (i.e., intended to relate to the user's prior knowledge or experience), usually interactive, and postable to a learning object repository (LOR). The growth of online learning object repositories may ultimately support a common definition of a learning object as digital or tagged with digital resources. But for now these authors prefer a broad definition of a learning object as "anything that has pedagogic value - digital or non-digital... as long as it can be contextualized by individual learners". The advantage of this definition is that it enables a clear unitary description of any pedagogically sound learning activity, even including a well managed or facilitated online discussion forum/board as argued by Harman and Koohang (2005). Clickers (student response systems abbr. SRS) allow the assembly/disassembly of broad subject matter into component structural elements, ideas, concepts, and ways of thinking. This chunking of broader topics into components generates granular (or "low granularity") learning objects as described by Fournier-Viger, Najjar, Mayer, and Nkambou (2006). The best practices of clicker pedagogy meet these criteria, promoting interactive and contextual learning that is entirely consistent with the identity of clicker objects as learning objects. This paper describes student response systems, how clicker activities are designed, how they are implemented and how they work in a classroom. The rationale and structure of clicker-based learning objects are defined and their potential impact in courses redesigned to integrate student response systems is discussed.

\section{Clickers Promote Learning}

Clickers have been in college classrooms since the early 1990s (Beatty, 2004); reliable, easy-touse systems have been available since 1999. Students answer multiple choice or similar questions projected on a classroom screen by pressing keys on a clicker keypad resembling a small calculator or TV remote control. The students' keystrokes are transmitted to a receiver attached (usually via a USB port) to a computer at the front of the classroom. Clicker software records student responses from which the instructor can generate reports. In part through the marketing efforts of textbook publishers, but mostly because they offer unprecedented student learning opportunities (Beatty, 2004; Mazur, 1997), they are becoming increasingly popular with college instructors (Gilbert, 2005). An example, EDUCAUSE Pocket Edition \#4: ClickersPocketEdition004.mp3, can be found at http://connect.educause.edu/files/active/0/PocketEdition004.mp3

Pedagogic benefits of clickers include:

- increased class participation

- better formative assessment of student learning

- instant feedback on student retention and learning to both student and instructor

- involving all (not just a few) students in critical thinking exercises.

- increased opportunities for student-student interaction in large lecture classes

- increased opportunities for student-faculty interaction in class

- increased student attention and awareness in class, even at 8:00am or 6:00pm

- more lively engagement of students in an altered lecture hall atmosphere.

- improved attendance

Beatty (2004) described a typical use of clickers in which the instructor poses a question or problem in class, posting it as a clicker question slide. Students are encouraged to discuss a problem among themselves for several minutes, after which they individually key in an answer choice from among several response options. The instructor then brings up a histogram of student responses and can moderate further class discussion, even before revealing the correct answer. A variation on this theme routinely used by this author is to require students to answer a question first, without class discussion. If too few students know the answer (based on the histogram), class discussion is allowed and students get a second chance to answer the question. These 
strategies bring the classical think-pair-share learning paradigm, usually associated with small classes, into the large lecture hall. The key learning elements here are a thought provoking concept question and student-centered collaborative learning by critical thinking. The act of turning over some classroom control to students is revolutionary to some, but "can dramatically transform the classroom environment and the entire learning dynamic for a course" (Beatty, 2004). Clickers are effective in large and small classrooms and even in lab classes. But they are especially potent in the redesign of course instruction in large lecture halls. In sum, clickers are changing how we teach and how students learn.

Recognizing their obvious pedagogic potential, four University of Wisconsin campuses (including UW-Milwaukee) provided incentives for expanded clicker use as part of a comprehensive inter-campus study of satisfaction and learning benefits of clickers. For more information about this project, visit http://www.uwm.edu/Dept/LTC/srs.html\#grant.

Rigorous analysis of data for this project is still in progress, but raw data can be seen at http://www.uwm.edu/Dept/LTC/docs/JointITSRS.ppt. An Excel ${ }^{\mathrm{tm}}$ file showing informal results of an end-of-semester student survey in the author's course is at https://pantherfile.uwm.edu/xythoswfs/webui/ xy-2725353 1-t q7Yp4bBJ ${ }^{1}$. Both data sets show overwhelming student satisfaction with clickers, and positive perceptions on how they affected learning. The general principles of designing clicker presentations are similar, making it easy to introduce them into any classroom with a computer. Several popular clicker systems are integrated into or designed to work with the popular PC-based Microsoft PowerPoint ${ }^{\text {tm }}$ software. Adopting clickers means preparing presentations, delivering them and saving student response data, steps that vary with clicker brand. Presentations are made from a classroom (podium, or laptop computer with projector). After launching the presentation software program(s) and loading a class roster, the class presentation can begin. After the presentation, student response data is saved and reports generated and analyzed. The rest of this discussion is based on our experience with TurningPoint ${ }^{\mathrm{tm}}$, the system selected for support at UW-Milwaukee in part because it works from within PowerPoint ${ }^{\mathrm{tm}}$

The most creative step, generating questions and response options, is also technically the easiest step. To illustrate, the typical PowerPoint ${ }^{\mathrm{tm}}$ opening slide appears after launching TurningPoint ${ }^{\mathrm{tm}}$, but with an additional TurningPoint ${ }^{\text {tm }}$ (plug-in) toolbar. Clicking insert slide on this toolbar drops a window and clicking on the first option opens a new slide that looks like a second PowerPoint ${ }^{\mathrm{tm}}$ template slide, except that it contains a default vertical bar graph. To create a clicker (interactive) slide, one may simply type the question in the upper text box and each possible response in the lower text box. Though integrated into a full slide presentation, a clicker slide (or a group of related slides including a clicker slide) could qualify as a learning object.

\section{Clicker Units as Learning Objects}

Learning objects are not typically instructor-administered, but are self-contained objects that students can interact with individually or in groups. Clickers used in a classroom require instructor facilitation; even if clicker presentations are made available to students outside of class, they would not be interactive unless students have the clicker software (possible, but generally not the case). While the learning object status of a series of clicker slides is transient and confined to the in-class presentation, the idea of a managed learning object is not new. The definition of a discussion forum as a learning object discussed above is also subject to the limitations of management and impermanence. Clickers and discussion threads are learning objects in the same sense

${ }^{1}$ If links in this article malfunction, please contact the author. 
that performance art is art - they have learning (or in the case of art, aesthetic) value despite their transience.

Existing PowerPoint ${ }^{\mathrm{tm}}$ presentations were the starting point for introducing clickers into a biology course for majors. After opening and reviewing the presentation in TurningPoint ${ }^{\mathrm{tm}}$, appropriate places for interactive slides were identified in the presentation and then inserted and composed as described above. It was only necessary to review the slides before and after each interactive (i.e., clicker) slide and modify them to ensure smooth transitions during the presentation. By a minimal definition of a learning object as an interactive learning module (albeit instructor-mediated), each clicker slide could be an interactive learning object. A stronger learning object could be a series of one or more clicker slides covering a proscribed topic/concept, together with appropriate introductory, explanatory and summary slides. An entire presentation could contain several such related Clicker Unit learning objects. For an example on principles of cellular polymer synthesis and degradation, visit https://pantherfile.uwm.edu/xythoswfs/webui/ xy-2725386 1-t ArHivgs6 (For best effect use TurningPoint ${ }^{\text {tm }}$ to view).

\section{The Evolution of Clicker Sets as Learning Objects}

In the author's original, non-clicker presentations illustrations or descriptive text would be followed by questions relating the material to a broader concept (a concept question) or requiring interpretation of data from an experiment (a conclusion question). Students who raised their hands would try to address the question. Based on a given answer, the class would be asked if there was anyone who thought otherwise, occasionally provoking discussion. The next mouse click would bring up the correct answer. PowerPoint ${ }^{\mathrm{tm}}$ presentations were routinely posted to the course website in our course management system for students to review, print and bring to class for more efficient note-taking. A need to maintain two sets of slide presentations quickly became clear: a non-clicker presentation for student access, and a clicker version for class presentation. After delivering the classroom (interactive) presentation, it too was posted to the website so students could study and review the clicker questions before exams.

This strategy worked well until, because of ongoing revisions and improvements, the classroom clicker presentations began to depart significantly from their unaltered non-clicker counterparts. To keep the latter current, it was easiest to strip revised clicker presentations of their interactive content and then tweak them to smooth the transitions between affected slides. In other words, if the process of introducing clickers was forward movement, then the revision of the TurningPoint ${ }^{\mathrm{tm}}$ and their cognate PowerPoint ${ }^{\text {tm }}$ presentations was in essence the reverse process. Perhaps counterintuitive, nevertheless this path opened new pedagogic possibilities. Conceptual or interpretive critical thought questions are still emphasized in the non-clicker presentation, but without the constraint that the questions had to be answered in the presentation. Instead, the questions were left open-ended. Students could think about these questions and even look for answers before coming to class. In class, the interactive clicker presentations engage students in collaborative discussion of and response to related questions, further assessing and reinforcing their understanding in a learning community of classroom neighbors. The first Clicker Sets emerged from this process.

A Clicker Set is a paired series of slides taken from non-clicker and clicker presentations containing matching concepts, experimental descriptions, illustrations and/or animations. Slides from the clicker presentation incorporate the interactive questions used in the classroom. The matched slides from the non-clicker presentation include questions identical, similar, or related to those in the clicker presentation, but without answers. Students are instructed to view the available nonclicker slide shows, research and answer the open-ended questions therein. They could even record answers on their printouts. Well- designed clicker sets are potent learning objects in which critical thinking begins at home. It continues in class where clickers engage students in discus- 
sion and offer immediate feedback on their thinking about previously encountered content. Offering some points towards a course grade could be an incentive to home-participation by students. This could be done by linking the non-clicker questions to online quizzes (e.g., in a course management system), or to an open-ended format in a discussion forum, raising the ante even further on the definition of a learning object. A Clicker Set on cellular polymers can be found at https://pantherfile.uwm.edu/xythoswfs/webui/ xy-2725379 1-t XSEOqFmI (opens in PowerPoint $^{\mathrm{tm}}$; save and view with TurningPoint ${ }^{\mathrm{tm}}$ for best effect). An example about enzyme mechanisms (adapted from Freeman, Scott, Biological Science, 2/E, c 2005, pp. 65, 67. It is electronically reproduced by permission of Pearson Education, Inc., Upper Saddle River, New Jersey) can be found at https://pantherfile.uwm.edu/xythoswfs/webui/_xy-2725382_1-t_OI8kufIj (opens in PowerPoint ${ }^{\mathrm{tm}}$; save and view with TurningPoint ${ }^{\mathrm{tm}}$ for best effect).

\section{Conclusion}

Learning objects contain autonomous, adaptable and low granularity information objects (Fournier-Viger et al., 2006). The Clicker Sets described here are autonomous in that they do not require linkage to external data for understanding or definition. They are adaptable in that they are open to as little or as much user-modification as desired. Clicker Sets also qualify as low granularity packets of information that can stand alone or be assembled as part of larger objects. Finally, Clicker Sets begin life as interactive and therefore learner-centered, a preferred feature of learning objects. Tagged with appropriate metadata for identification and indexing, the Clicker Set learning objects (modeled in this study) are easily integrated into any PowerPoint ${ }^{\text {tm }}$ presentation. Any group of related Clicker Sets assembled in logical order as a topic or even into a complete course could be defined as a high granularity learning object. But because they are offered as PowerPoint ${ }^{\mathrm{tm}}$ presentations, full course-length clicker-based learning objects remain easily parsed and re-assembled, as well as infinitely changeable modifiable by an end-user.

There is a growing acceptance of clickers as tools to enhance learning and student engagement (Beatty, 2004; Mazur, 1997), but we have only begun to realize their potential in redesigning courses. Student response systems are far more that mere multiple choice/true-false quizzing or attendance-taking tools. By combining text, graphics, animations and even audio components, they can foster multi-dimensional learning (teaching to different learning styles), collaborative learning, problem-based learning, and the development of critical thinking skills. Their potential spans all academic disciplines, and is especially useful in redesigning large lecture courses to treat students as critical thinkers instead of simple memory banks (which of course they are not!). Like all good learning objects, Clicker Units or Sets can be used as created, modified, or simply as a template or guide for anyone wanting to create their own versions de novo. In exemplary terms, the combination of self- and instructor-managed interactive activities in Clicker Sets is a 'next step' in the use of student response systems. In practice, they are the natural consequence of doing what we instructors already do when we develop and revise our lecture slides in the interest of better pedagogy.

\section{References}

Beatty, I. (2004). Transforming student learning with classroom communication systems. Educause Research Bulletin, (3), 2-13. Available at http://www.educause.edu/ir/library/pdf/ERB0403.pdf

de Salas, K. \& Ellis, L. (2006). The development and implementation of learning objects in a higher education setting. Interdisciplinary Journal of Knowledge and Learning Objects, 2, 1-22. Available at http://www.ijklo.org/Volume2/v2p001-022deSalas.pdf

Fournier-Viger, P., Najjar, M., Mayer, A. \& Nkambou, R. (2006). A cognitive and logic based model for building glass-box learning objects. Interdisciplinary Journal of Knowledge and Learning Objects, 2 , 77-94. Available at http://www.ijklo.org/Volume2/v2p077-094Fournier-Viger.pdf 
Gilbert, A. (2005). New for back-to-school. CNET News.com, August 5, 4:00AM PDT.

Harman, K. \& Koohang, A. (2005). Discussion board: a learning object. Interdisciplinary Journal of Knowledge and Learning Objects, 1, 67-76. Available at http://ijklo.org/Volume1/v1p067077Harman.pdf

Johnston, S. (2001). Flexible teaching and learning at the University of Tasmania: Some strategies to move us forward. University of Tasmania internal paper.

Mazur, E. (1997). Peer instruction: A user's manual. New Jersey: Prentice Hall.

Wiley, D. A. (2000). Connecting learning objects to instructional design theory: A definition, a metaphor, and a taxonomy. In D. A. Wiley (Ed.), The instructional use of learning objects: Online version. Retrieved August 10, 2006 from http://reusability.org/read/chapters/wiley.doc

\section{Acknowledgement}

The author would like to thank Alan Aycock of the Learning Technology Center of the University of Wisconsin-Milwaukee for his reading and helpful suggestions in the preparation of this article.

\section{Biography}

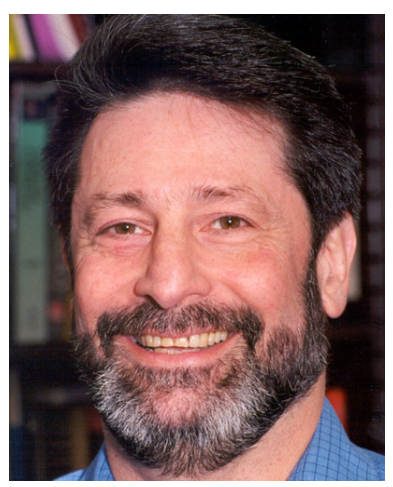

Dr. Gerald Bergtrom is a Professor of Biological Sciences a Course Redesign Consultant in the Learning Technology Center at the University of Wisconsin-Milwaukee. He has 32 years of experience in research and teaching (e.g., introductory biology for majors, cell biology, molecular biology, etc.). In addition to many research articles on gene structure and evolution, he has published articles on cell biology and genetics for secondary school students and is participating in a major, multi-university study of student response systems at four University of Wisconsin System universities. He has also reviewed biology learning objects for MERLOT. 